Had it waited for the separation to be imposed from outside, no wedge need have been driven between its members, many of whom feel strongly and bitterly on the subject; the library profession would not have inflicted a gratuitous insult and slight on its non-white members and through them on their peoples; professional bodies such as the Library Association and the American Library Association, who would doubtless have offered support and sympathy when Government action enforces the establishment of separate associations, would not have been alienated and antagonized; librarians would not have set themselves apart from professional bodies in South Africa, several of whom have already expressed. concern at the inevitable consequences of the Government's proposed legislation; and finally, the Association would not have played into the hands of South Africa's critics at the United Nations and elsewhere.

\section{Documentation of Science Organization}

AN interesting paper by G. Rózsa on "Documentation of Science Organization as an Emerging New Branch of Scientific Information" has been issued as No. 32 in the Bibliographical Publications of the Scientific Academy of Hungary (Pp. 15. Budapest: Magyar Tudományos Akadémia Könyvtára, 1962). Directing attention to the prolific growth of scientific organizations, in size and number as well as in scope, Dr. Rózsa suggests that documentation of scientific organization involves covering the following fields: history, theory, philosophy and systematization of science; scientific policy and government administration of scientific work; international collaboration in scientific work; planning management and organization of scientific work; levels of research; methodology of research work; economic problems of scientific work; management of scientific manpower; scientific personnel; scientific agencies and organizations; and scientific information. The first nine of these divisions he regards as containing the concept, themes and systematization of the necessary documentation, but this, he maintains, does not fit into any of the developed and usual schemes of science systematization, or even library or documentary systematization; however, it is probable that not all his readers are likely to accept the contention that science organization, in consequence, appears as a new branch of science. It is quite clear, however, that Dr. Rózsa uses the term 'discipline' in a sense which differs considerably from that in which it is used in academic circles in Britain or in the United States. $\mathrm{He}$ is concerned to see that efficient means are developed of handling the problem of communication or of documentation of scientific organization, whether on a general basis or within a particular field of science.

\section{Magnetic Recordings}

A REVISED bibliography on Magnetic Recordings, compiled and edited by R. E. Hadady and published by Kinelogic Corporation, 29 South Pasadena Avenue, Pasadena, California, covers the years 1954-61 inclusive, and lists 775 papers and articles from some 120 technical journals. An author index is included and both the names and addresses of the journals cited are given. The numbers of items for the respective years 1954-61 are 95, 62, 67, 70, $55,63,159$ and 204, and they show how the interest in the subject of magnetic recording has varied, with a considerable revival and growth in the more recent years. The bibliography will be of interest to those engaged in data recording, data storage and retrieval, recording design, automation, and sound and television recording.

\section{Southern Variable Stars}

Astronomy has for long suffered from the lack of observations of objects in the southern hemisphere, and the increased tempo of results which has followed the installation of the 74-in. telescopes at Pretoria and Canberra is most welcome. The latest issue of Monthly Notices of the Royal Astronomical Society (125, No. 5/6; 1963) contains two contributions on southern variable stars. M. W. Feast (pp. 367-415) describes very extensive observations of long-period variable stars made at the Radcliffe Observatory, Pretoria, during the years 1952-60, when 281 spectra of 114 stars were obtained. Radial velocities were obtained from this material; for only a very few of these stars had similar observations been made previously. The velocities were obtained from both absorption and emission lines. Combination with data for northern stars yielded a very homogeneous set of velocities for 405 long-period variables. These data were subjected to statistical analysis for systematic motions, velocity ellipsoids and galactic rotations. The variables cover a wide range of population types. The shortest period variables have anomalous motions and may perhaps be pulsating in the first overtone. A. W. Rodgers and R. A. Bell (pp. 487-527) report on an analysis made at the Mount Stromlo Observatory, Canberra, of highdispersion spectra of the southern cepheid variable $x$ Pavonis. This is a relatively bright star and is probably a member of the disk population somewhat similar to $W$ Virginis cepheids. Variations in the parameters describing the atmosphere of the star were obtained at various phases of the cycle, and the density fluctuations studied. The abundances of the chemical elements in the star were also obtained.

\section{The Zone of Fracture, and the Wave Spectrum of Earthquakes}

DR. HANS BERCKHEMER has examined this question and written about it in a paper entitled "Die Ausdehnung der Bruchfläche im Erdbebenherd und ihr Einflub auf das Seismische Wellenspektrum" (Gerl. Beitr. Z. Geophys., Bd. 71/1). The amplitude-period spectrum of a seismogram is determined by what happens in the focal zone as well as by the conditions of wave propagation and the characteristics of the seismograph. Dr. Berckhemer describes a method which admits the separation of the influence of the focal process from the others. His investigation covers 20 earthquakes of magnitude from $4 \cdot 5$ to 8 . It can be seen immediately that long-period waves are favourably excited by strong earthquakes. The comparison of isoseismal maps suggests that differences in the wave spectrum are caused by the different sizes of the fractured zones at the hypocentre. A simplified theory for a focal process with an extended focus is given in order to explain the observations. The assumptions made concerning the rupturing velocity are based on the results of laboratory experiments. Dr. Berckhemer has found that the relationship $\log F=0.45+1 \cdot 7 M$ between the earthquake magnitude, $M$, and the size of the fractured area in square centimetres, holds for values of $M$ between 5.5 and 8 . A corresponding expression in terms of earthquake energy instead of magnitude is $\log F=0.85$ log $E-5 \cdot 7$. By comparing the last formula with an expression for the elastostatic energy of the fractured area given by Keylis-Borok, it is possible to obtain information about the shape of the seismic fault and to determine the shearing strength of the crust in the focal area $\left(2-5 \cdot 10^{7}\right.$ dynes $\left(\mathrm{cm}^{2}\right)$. Deviations from laboratory measurements may be explained by stress concentration at geological scars within the Earth's crust.

\section{Powder Technology}

A COURSE of instruction in "Powder Technology" will be held in the Faculty of Engineering, King's College, University of London, for one year commencing in October. The course is designed for students with a first degroe in engineoring, physies, chemistry or certain other approved branches of applied science, and its successful completion will lead to the award of a College postgraduate 